\title{
Kantaantekeninge by die prediking
}

DS. N. P. HEYSTEK

\section{INLEIDEND}

Die opskrif bevat twee kernbegrippe wat om die volgende redes nadere toeligting verdien:

a. 'n vroegtydige aanduiding van wat onder die uitdrukking "kantaantekeninge" en "die prediking" verstaan word, behoort verhel derend by te dra tot die oogmerke wat vir hierdie voordrag gestel is;

b. Die begrippe word doelbewus aangewend om te dien as aanduiding én as begrensing van die stof wat in behandeling geneem word.

As uitvloeisel van bogenoemde word die volgende inhoude en/of oogmerke aan die onderskeie begrippe toegeken:

- Die prediking: 'n beknopte omskrywing van die begrip prediking word beoog; verder word 'n seleksie van die vernaamste wesenselemente van die prediking gedoen en behandel (vgl. "kantaantekeninge" hieronder).

Die bepalende lidwoord by prediking toon aan dat 'n Skrifgefundeerde omskrywing van prediking nagestreef word. Die volle spektrum van die prinsipiae van die prediking behoort slegs aan die Skrif ontleen te word. Aangesien 'n eksegeties-analitiese metode vir hierdie Skriffundering nie in so 'n beknopte weergawe haalbaar is nie, behoort die bevindinge wat in hierdie voordrag aangebied word nogtans die resultate van 'n eksegeties-sintetiese navorsingsmetode te weerspieël.

- Kantaantekeninge: Hierdie begrip is in die opskrif bygevoeg om dit moontlik te maak om 'n willekeurige seleksie van aspekte rondom die prediking te maak, aangesien álle aspekte van die prediking nie met hierdie beknopte aanbieding behandel kan word nie. Verder bevat die woord "kantaantekeninge" die voordeel dat enige aspek wat tot die prediking gereken word, aangesny kan word.

Onderstaande elemente van die prediking is gekies aangesien dit, in volgorde, die noodsaak sowel as die vernaamste kernelemente van die prediking weergee. Die prediking van die belydenisskrifte word bygeneem as evalueringsaspek:

- die primaat van die prediking;

- die inhoud van die prediking;

- die wese van die prediking, en

- die prediking van die belydenisskrifte.

Die uitwerking en aanbieding van die stof word in bogenoemde chronologiese volgorde gedoen. 


\section{DIE BEGRIP PREDIKING}

Die begrip prediking word ontleen aan die Latynse woord praedicatio, wat min of meer die inhoud van die begrip kèrussein weergee; d.w.s. die verkondiging van 'n publieke boodskap deur ' $n$ herout acon die volk (Jonker, $1960: 500$ ). Runia toon aan dat die Latynse begrip praedicare ' $n$ tweede betekenis besit, $\mathrm{nl}$ : om te loof en te prys $(1983: 20)$. Hiermee kom die doel van die prediking in die gesigsveld, naamlik Godsverheerliking (Jonker, 1976:60).

Wanneer in gedagte gehou word dat die Nuwe Testament nie minder as dertig begrippe aanwend om die inhoud, wese, doel en ander fasette van die prediking weer te gee nie (vgl Friedrich, 1965:703), en die Ou Testament nie minder as sewe nie (Harder, 1960:162; Müller-Bardorff, 1969:167), word besef hoe moeilik dit is om 'n keuse te maak van ' $n$ verteenwoordigende en aanvaarbare term.

Tradisioneel word die woord Homilet ek as vakterm en vakomskrywing aangewend.

Hierdie term wat sedert die tweede eeu in gebruik is, is ' $n$ uitbouing van die begrip homilein wat slegs in Hand 20:11 voorkom en in die NAV met "praat" weergegee word. Dit word gebruik as beskrywing van die besonder "uitgerekte" prediking van Paulus te Troas. Van der Walt (1983:25) kies egter die begrip kérussein: "Dit is (egter ook) duidelik dat kérussein die kern van die prediking vorm, waaraan die ander benaminge noodsaaklike elemente van die prediking toevoeg." Hoekstra ag die omskrywing diakonia toū lōgou "bijzonder geschikt" ( $\mathrm{s}$ : 157). Dit is egter inderdaad te betwyfel of aan enigeen van die talle Bybelse begrippe 'n sentraliteit of prioriteit bo die ander verleen kan en mag word. Om die rede is dit baie bevredigend dat ook die Afrikaanse taal die saak van prediking in verskeie terme weergee, soos: spreek, bekend maak, verkondig, preekkunde, prediking, preek, woordverkondiging en boodskap.

Uit bogenoemde materiaal blyk dat die begrip prediking 'n sodanige veelsydigheid en kompleksiteit besit dat dit haas onmoontlik volledig in 'n definisie omskryf kan word. Dit staan egter uit bogenoemde kort oorsig reeds vas dat die prediking sien op die amptelike bediening van die Woord (vgl Kotzé, 1963:24). 'n Poging om die prediking nader te definieer, word aan die einde van hierdie voordrag gedoen.

\section{KANTAANTEKENINGE BY DIE PREDIKING}

Die kantaantekeninge by die prediking word ook in volgorde behandel soos hierbo vermeld.

\section{DIE PRIMAAT VAN WOORDVERKONDIGING}

Die bewaring, uitbouing, opbouing en vermeerdering van die kerk word vandag langs verskillende weë gesoek. Die volgende onderwerpe staan hoog aangeskrewe om die kerk aktief betrokke te mak by resente en aktuele werklikhede: die politiek, kommunisme, wêrelddiakonaat, inspraak in wetgewende en uitvoerende gesagsinstansies, ekumene en kerklike feesdagprogramme. Alhoewel sommige van hierdie aspekte ' $n$ belangrike bydrae lewer tot kerkbele- 
wing en opbouing, word die stelling onomwonde gemaak dat die bediening van die Woord die primat behoort te beklee onder alle bedieninge en aktiwiteite ten behoewe van die stigting, opbouing en bewaring van die kerk.

Wanneer Paulus sy betoog oor die redding van Israel en die heidene in Rom 10:1-21 afsluit, konkludeer hy: "Die geloof kom dus deur die prediking wat 'n mens hoor" (NAV, v 17). Hierdie konklusie van Paulus behoort baie ernstig geneem te word. Die geloof word nie deur indrukwekkende kerklike programme en kerklike bedrywighede by "lidmate" en "nie-lidmate" gewek en onderhou nie, maar doodgewoon deur die prediking van die evangelie (vgl Joh $20: 20-23$ ). Ook die opbou en toerusting van die reeds ge!owiges geskied nie anders as deur die "kennis" en "waarheid" wat verkondig word deur apostels, profete, evangeliste, herders en leraars nie (Ef 4:11-16). Die "kennis" en "waarheid" waarna in die voorafgaande verwys is, bevat in die konteks van Ef $4: 11-16$, 'n sterk Christologiese aksent. Daarmee word bedoel dat die inhoud van die "kennis" en "waarheid" in Christus te vind is (vgl v 13: "kennis van die Seun van God" en v 15: "proei na Christus toe"). Die apostels was op hulle hoede daarvoor dat geen ander, hoe noodsaaklike diens ook al, en nood of eis van die gemeenie. die Woordbediening mag verdring nie. In Hand $6: 1-6$ word die situasie geteken van 'n ernstige fisiese nood in die gemeente van Jerusa lem aangesien die weduwees van die Griekssprekendes oor die hoof gesien is in hul daaglikse versorging.

Hiermee word die nood van dreigende groepvorming of tweespalt sowel as groot armoede aangedui (na analogie van die sinagogale praktyk is lidmate met geen inkomste nie, daagliks versorg). Die apostels laat hulle egter nie "insleep" in hierdie noodsituasie nie, maar stel bekend: "Dit is nie reg dat ons die verkondiging van die woord van God verwaarloos om die versorging te kan behartig nie" (Hand 6:2). Daarom is ánder broeders verkies om hierdie noodsaaklike diens te verrig, terwyl die apostels "al" hul aandag aan gebed en bediening van die Woord bly gee het (Hand 6:4). Vind die teenoorgestelde nie juis vandag in baie gemeentes plaas nie deurdat die predikant - wat meestal ook slegs alleen in die gemeente staan - by allerlei dinge en sake binne sowel as buite die gemeente betrek word? Die negatiewe gevolg is dat die enigste leraar soms nie meer tyd het vir "gebed sonder ophou" (1 Tess 5:17), en vir bestudering en verkondiging van die Woord, in "gunstige en ongunstige" tye nie ( $1 \operatorname{Tim} 4: 11-16)$. Baie gemeentelede vind dit moeilik om die leraar slegs af te sonder vir hierdie één geestelike saak: hy word teen wil en dank (of soms danksy homself?), bestuurder, organiseerder, bouer, administrateur en verteenwoordiger van die gemeente gemaak. Om hierdie rede is dit nie verbasend dat kerke ernstige geestelike insinkinge ondergaan nie. Omdat die leraar nie 'n leerling van die Skrifte bly nie (Calvyn), is selfs ook die geleentheid wanneer hy wel as leraar optree nie werklik geslaagd nie, en word dit nie gedra deur 'n borrelende entoesiasme en begeerte om te verkondig nie. Alhoewel die effektiwiteit van die prediking berus by die kragtige werking van die 
Gees (1 Kor 2:6-16; Knox, 1957:89), wil die Gees tog deur en met die prediker as instrument werk (Jonker, 1976:31-37).

Die boek Handelinge getuig in sy geheel van die belangrikheid van die Woordbediening (vgl. Lloyd-Jones, 1971:20-5). Na die uitstorting van die Gees word Petrus deur die Gees aangevuur tot 'n onbevreesde en kragtige prediking (Hand 2:1-36); selfs Stefanus, die diaken, "vol van die Heilige Gees" (Hand 6:5), word aangevuur tot moedige prediking (Hand 6:15-7:53). In Hand 4, 5 en 8 word beskryf hoe God vervolginge gebruik het om die gemeente te dwing tot gehoorsaming aan sy opdrag soos vervat in Matt 28 : 19: "Gaan dan na al die nasies toe en maak die mense my dis. sipels" (NAV; vgl. ook Mark 16:14-18; Luk 24:36 - 49; Joh 20:19 - 23; Hand $1: 6-8)$. Uit die feit dat die klem van die Woordbediening in Handelinge sekerlik val op sending (heidene) en evangelisasie (Jode), kan afgelei word dat die geloof deur Woordbediening (HK, antw 21) gewek word. Uit al die briewe van die NT is duidelik dat die gestigte gemeentes bly voortleef en geestelik gegroei het deur niks anders nie as voortgesette prediking.

Dit is selfs aan te toon dat die dade, wonders en handelinge van God in die Ou sowel as Nuwe Testament begelei en verklaar word deur Woordbediening (vgl. Runia, 1983:21-4). Van die duidelikste voorbeelde in dié verband is te vind in die boeke Deuteronomium (prediking van Moses op grond van die wetgewing en historiese dade van God) en die evangelie van Johannes waar die wonders en woorde van Christus tot prediking saamsmelt. Die wonders en tekens dien as Godsopenbaring (semēion). Om dié rede kan Johannes dit as sodanig aanwend.

Lloyd-Jones toon aan dat die prediking geen substituut in die kerk het nie aangesien dit deur die prediking, as krag en wysheid van God ( 1 Kor $1: 18-2: 16$ ), is dat die mens met God versoen word en so die tydelike en ewige lewe ontvang (1971:26-44). Waar die prediking in suiwerheid gebring word, word die gemeente ook pastoraal versorg en in sy primêre nood bedien (Lloyd-Jones, 1971: $37 \mathrm{ev})$.

In hierdie verband is dit belangrik om ook 'n paar opmerkinge te maak oor die krag of effektiwiteit van die prediking. Friedrich stel dit kernagtig: The Word proclaimed is a divine Word, and as such it is an effective force which creates what it proclaims. Hence preaching is no mere impartation of facts. It is an event. What is proclaimed takes place (1965:709). Calvyn het nie gehuiwer nie om te skryf: "Wanneer die evangelie gespreek word, vermeng die bloed van Christus met sy stem" (Kommentaar op Hand 9:21; $10: 19)$.

Alhoewel die Woord van God deur swakke werktuie gebring word, word die heerlikste beloftes daaraan verbind: Deut $32: 2$ vergelyk die verkondiging met reënwater, dou, sagte reën, en reënbuie op die grassies en op die graan; Jes $55: 10,11$ noem die woorde van God reën, sneeu wat uit die hemel kom en nie "onverrigter sake terugkeer" (NAV) nie; ook Ps 29:3-11 besing die kreatiwi teit van die stem van God, terwyl Hand 4:12 spreek van die indringende werksaamheid van die Woord wat selfs die "gedagtes 
en bedoelings van die hart... beoordeel" (NAV). Laastens vermeld ons die feit dat gespreek kan word van 'n aposto!iese preeksuksessie. Die apostels het die eie Woord van God gebring (vgl. 1 Tess $1: 6,8 ; 2$ Tess $3: 1$; Kol $1: 25 ; 4: 3 ; 2$ Tim $2: 9 ; 4: 1 ; 1$ Pet $1: 23 \mathrm{ev}$. Hul medewerkers en "opvolgers" se prediking ontvang dieselfde karakterisering ( 1 Tess $3: 2,3$; 1 Kor $16: 10 ; 2$ Tim $2: 2$; $4: 2$ ). Op hul beurt moet die evangelie toevertrou word aan betroubare manne wat ook bekwaam sal wees om ander te onderrig... éwe gesagvol en met stééds dieselfde $\mathrm{krag}$ omdat die evangelie 'n "krag" en "wysheid" van God is en bly (gen subjectivus) wat nie aan mense gedelegeer word nie. Die mens is slegs instrument. Bullinger het dit so verwoord: God Himself spoke to the fathers, prophets and apostles and still speaks to us through the holy Scriptures (Tweede Helvetiese Konfessie).

\section{SAMEVATTEND}

Ons as predikers moet toesien dat die bediening van die Woord en die gebed op Sondae, en in die week, tydens katkisasie, huisbesoek en ander pastorale besoeke, ongehinderd en met die grootste vrug moontlik voortgaan. Naas sy eie diens, Woordbediening en gebede het die plaaslike leraar(s) 'n besondere taak om veral die ouderlinge en diakens toe te rus om ook as Woordbedienaars (in hul wyke) op te tree. Uiteindelik roep God elke gelowige om 'n herout van sy evangelie in die wêreld te wees (Joh $20: 21-23$ e.a.).

Die geloof, geesteskrag en -werke van die gemeente voed primêr op Woordbediening, terwyl ander diakoniae en werkinge ( 1 Kor $12: 1-11)$ komplementêre bydraes tot gemeentebelewing en -groei lewer.

\section{INHOUD VAN DIE PREDIKING}

De Klerk gee die inhoud van die prediking kernagtig weer as "deurligting van die sonde, verlossing en dankbaarheid" (1977:15). Die vraag is egter of dit as korrek aanvaar kan word.

Die saak wat hier uitgemaak moet word is: wil die prediking die mens in sy persoon, aard en sonde in die lig van die Skrif ontbloot (antroposentries); wil die prediking die wêreld in sy totstandkoming en bestaan verklaar (ontologies/kosmologies) en/of gaan dit in die prediking om die openbaring van God Self (teofanie). Hierdie vrae is baie belangrik aangesien die prediking nie

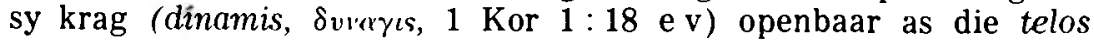
(doel, oogmerk) van die Skrif (Godsopenbaring) nie verdiskonteer word nie.

$\mathrm{Na}$ ons oordeel is die preekinhoud saam te vat as die selfopenbaring van God (Van der Walt, $1983: 55,85$ ). God is tegelyk die subjek sowel as die objek van die openbaring (Luk 24:44). Dit gaan nooit in die prediking oor die mens op sigself nie. In soverre die mens en die wêreld ter sprake kom in die prediking, word dit gedoen binne die verhouding, die relasie, wat daar tussen God en sy skepping (wêreld, mens; Gen 1,2) bestaan. Aan hierdie grondliggende verhouding word ook die verbondsmatigheid van die prediking ontleen (Gen 12:1; 15:1; Eks 3:1 e v; ea). 
Dit is verder uit die Skrif duidelik dat die inhoud van die Godsopenbaring ' $n$ besondere swaartepunt of aksent ontvang in Jesus Christus (vgl. 1 Kor $1: 18-2: 16$; Ef $4: 13$ - 16; Rom $10: 14$ e.v.). Jesus word daarom genoem: die vleesgeworde Woord (Joh 1:918), die laaste en duidelikste openbaring van God (Hand 1:1-4). omdat juis Hý God kan verklaar, wat sélf God is (Joh 1:1 e.v.), en van die Vader kom (Joh $14: 10$ ). Daarmee ken die Skrif nog nie aan Christus 'n sentraliteit in die preekinhoud toe nie, maar word gestel dat God wel deur Christus plasties en helder bekendgemaak word. Dit sal daarom kortsigtig wees om slegs Christus tot objek en inhoud van verkondiging te neem (vgl. die Christolatrie of Chris. tomonisme). Drie-enig word gepreek, soos die duidelikste belig en bekend gemaak in Jesus Christus, die man van Nasaret, maar wat tegelyk God is. Ons konstateer dus 'n teologiese preekinhoud met 'n Christologiese swaartepunt ( 1 Kor $1: 18$ e v; Ef 4:13-16; Rom $10: 17)$.

As sleutel en metode om die inhoud van die preek telkens tydens die eksegetiese arbeid raak te vat, word aanbeveel dat gekies word vir die driedeling indikatief, imperatief en belofte, in soverre dit in elke preekdeel by deurlees en eksegese funksioneer (vgl. Coetzee, 1985: $17-28$ ). Formeel gesien kom die indeling ooreen met die vasalverdrae en die verbondsgrondslag (vgl. Deut $28: 1$ e.v.). In die verbondsterme volgens Deut $28: 1$ e v gee God eers 'n selfopenbaring ( $\mathrm{v} 1,2)$, daarna bepaal Hy sy verhouding tot die volk in opdragte en so word organies en deurlopend beloftes gegee ( $v$ 2 - 68).

In die indikatief word God se handelinge, werkinge en selfopenbaring bekend gemaak t.o.v. die verlede sowel as die hede. In die imperatief word die verhouding van God tot die mens/gelowige gestel in opdraggewing, gevraagde regstellings, ens. Let daarop dat dit in die imperatief nooit om die mens as sodanig gaan nie, maar in sy verhouding tot God. In die beloftes word God se heil én cordele met die oog op die toekoms bekend gestel. Dit spreek vanself dat wanneer oor die verhouding van indikatief, imperatief en belofte nagedink word, dit duidelik blyk dat die imperatief in die indikatief (primêr) en in die belofte (sekondêr) rus, en as sodanig in die preekinhoud moet funksioneer (vgl. Deut 32:1-47). Word dit nie gedoen nie, dan word enersyds in determinisme (oorbeklemtoning van indikatief en belofte) of andersyds in moralisme (oorbeklemtoning imperatief) verval (vgl. Van der Walt, 1983: 102). Die vraag kan gestel word of die belofte-element nie wesenlik tot die indikatief behoort nie. Inderdaad!, die terme word bloot onderskei om die handelinge van God in die verlede en hede (indikatief) en toekoms (belofte) te onderskei sowel as om die eie aard van die goddelike beloftes aan te dui (vgl. Coetzee, 1985 : 18 e.v.).

Uit bogenoemde blyk dat die prediking nooit tot inhoud kan of mag hê: die dogma van die kerk; die kanoniek van 'n Bybelboek; hooflyne van die openbaringsgeskiedenis as sodanig; politieke, etiese, wetgewende kwessies en soortgelyke sake nie. Daar moet duidelik op die kansel onderskei word tussen preekinhoud, teologie, sosiologie, psigologie en soortgelyke vakwetenskaplike inhoude wat mak. 
lik in preke opgeneem word. Nie alles wat teologies toelaatbaar sou wees, behoort tot preekinhoud nie, en nie alle sake waaroor in koerante, tydskrifte en boeke geskryf word, kan tot grondinhoud vir die prediking geneem word nie.

\section{KONKLUSIE}

Die preekinhoud is God se selfopenbaring in die Skriftuur (natuur buite rekening gelaat). Hierdie selfopenbaring ontvang 'n besondere helderheid in Jesus Christus se persoon en handelinge. Alhoewel die mens intens betrek word in die prediking en die prediking tot die mens as objek gerig word, word die mens an sich nooit inhoud van die evangelie nie. Die verhouding (relasie) tussen God cn mens behoort wel tot die inhoud van die prediking, aangerien God sy barmhartigheid en regverdigheid daarin openbaar (HK, S 4, 5).

\section{WESE VAN DIE PREDIKING}

Die wese van die prediking vind moontlik sy kernagtigste en duidelikste uitdrukking in 1 Pet 4:11a: "As iemand die gawe ontvang het om te preek, moet God deur hom aan die woord kom" (NAV; vgl. Van der Walt, 1985:6-9). Letterlik skryf Petrus: "As iemand spreek lalein) moet dit soos (hös) woorde van Goc' lóg,a theou) wees." Die kopula hōs identifiseer die preek met die woorde van God. Dit is die wesenlikste element van die prediking, naamlik dat God sélf wil en inderdaad spreek deur die mond van sy geroepenes. Bullinger het dit in die Tweede Helvetiese Konfessie (1566) soos volg bewoord: Praedicatio verbi Dei est verbum Dei (aangehaal deur Runia, 1983:23; vgl. Matt 10:40; Luk 10:16: Joh 13:20). Die kernvraag in hierdie verband is uiteraard: hoe moet gepreek word sodat die prediking gekarakteriseer mag word as verbum Dei. Waarvandaan ontvang, en hoe bring 'n mensje uit de stof opgerezen die woorde van God? (Calvyn: IV, III, I1.

Ook in hierdie verband het Bullinger in die Tweede Helvetiese Konfessie verhelderend geskryf: God Himself spoke to the fathers, prophets and apostles, and still speaks to us through the Holy Scriptures. Die predikers ontvang die Woord van God nie anders as deur die Skrif nie. In die Skrif het God Homself genoegsaam geopenbaar (Hand 20:27). Die blote voorlees of deurgee van die Bybel is egter nie prediking nie. Coetzee polariseer die wese van prediking enigsins as hy stel dat Skriflesing primêre prediking is - omdat God Self dan aan die woord is - terwyl die homiletiese bediening sekondêre bediening is vanweë sy feilbaarheid (1985: 17). Ware, korrekte prediking est verbum Dei (vgl. hierbo). Uiteraard is God aan die woord in die Skrifte, maar prediking veronderstel dat die woord herinterpreteer en heraktualiseer word ten aansien van die situasie vandag. The Bible not only warrants but even urges us, when as yet unknown situations arise, to preach the bibli. cal message in such a way that our sermon is a re-interpretation and re-actualization of the original message (Runia, 1983:90).

Daar moet deur die prediking 'n brug gebou word van die Skrifwoord na die konkrete situasie waarin die hoorder verkeer. Anders gesê: die relevansie van die eeu-oue Skrifwoord moet deur die pre- 
diker, vir die hoorder, aangetoon word - juis dit is die taak en wese van die prediking. Hierdie wesenstaak van die prediking geskied deur explicatio en applicatio van die Bybelgedeelte in ' $n$ konkrete situasie (Kotzé, 1963:24-9).

Bogenoemde uitsprake word gegrond op die prediking wat in die Skrif self te vind is. Neem as eenvoudige voorbeeld Paulus se Woordverkondiging aan die Korintiërs in 1 Kor $10: 6-13$. Hy neem as teks die handelinge van God met die (sondige) Israel tydens die woestynreis, en behandel dit op die volgende wyse: die sondes van Israel word by wyse van herinterpretasie en heraktualisering "oorgedra" na soortgelyke sondes in die gemeente van Korinte (vgl. 1 Kor $7: 1-10: 33$ ). Daardeur word die Godsopenbaring tydens die woestynreis selektief in uitleg en toepassing deurgetrek na die situasie van die Korintegemeente, asof God Self tot die Korintiërs spreek (vgl. 1 Kor $10: 11-13$ ).

Die herinterpretering en aktualisering van die Skrifteks word ook duidelik deur Jesaja en Esegiël geïllustreer. Jesaja (51:1-14) en Esegiël (33:21-29) preek na aanleiding van dieselfde teks, naamlik die belofte van God aan Abraham om aan hom en sy nageslag die land Kanaän te skenk o.a. $22: 17,18)$. Esegiël verkondig nou tydens die ballingskap dat die puinhope van Jerusalem nie opgehou sal word nie; terwyl Jesaja aankondig dat dit wel sal gebeur. Twee verskillende preke uit één teks en beide predikers is ware profete. Die verskil is te verklaar uit die oorbring na die situasie. Esegiël preek vir onberouvolles te Jerusalem (vroeë stadium van balling. skap), terwyl Jesaja vir berouvolles preek te Babilon (latere fase van ballingskap). In die geval van Esegiël staan die belofte van God steeds, maar 'n valse beroep word deur die volk daarop gedoen vanweë hul Godveragtelike lewe. In die geval van Jesaja het die tyd aangebreek, na die tugstappe van God en gevolglike berou by die volk, dat die belofte weer eens (vgl. boek Josua, e.a.) in vervulling kan gaan.

Uit bogenoemde blyk hoe belangrik die situasie vir die prediking is en dat dit juis veral op hierdie punt is waar die gawe van die prediking as goddelike geskenk benodig word. Ook word hier nie slegs dié gawe benodig nie, maar die konstante en onmisbare leiding van die Heilige Gees. Hy wat preek moet bo alles nie geleerdheid, kundigheid en selfs insig soek nie, maar hy moet 'n man wees van die Gees (Knox, 1957:89). Die Gees het nie slegs eenmaal die Woord gegee nie, maar spreek voort deur die Woord (Trimp, Calvyn, e a). Die prediker moet medewerker en nie teëwerker van die Gees wees nie. Runia maak t.o.v. die diens van die Gees die opmerking: Christ did his work for us, but without us, the Holy Spirit also does this work for us, but at the same time employs us in his service (1983:95). Calvyn was waarskynlik reg in sy oordeel dat die gawe van profesie vandag daarin gevind word dat die prediker die Woord korrek en onbevrees in ' $n$ bepaalde situasie uitlê en toepas (Deel III, IV, 4-8). Onlangs is in 'n ondersoek na die prediking uitgewys dat die meeste predikers daarin slaag om die explicatio suksesvol te volvoer $(70 \%)$, maar in die applicatio slaag slegs 30\%. (Berig: Koms van die Koninkryk. 
SAUK). Daarom is die vraag na die wyse van die aanbieding van die explicatio en applicatio van buitengewone belang.

Dit kan gestel word dat die explicatio en applicatio nie op mekaar behoort te volg soos twee trokke van 'n trein nie. Dit word in baie preke gevind: die explicatio van die Skrifdeel neem driekwart van die preek in beslag; teen die einde van die preek word na 'n toepassing, na analogie van die teks, of parallel daaraan, gespring. Die eerste driekwart mag wonderlike eksegese wees, maar is nie prediking nie, terwyl in die slotdeel die gevaar bestaan dat die gemeente die stem van God "verloor". Jonker pleit tereg vir 'n "naatlose" twee-eenheid in uitleg en toepassing wat deurlopend moet geskied (1976:38-47). Indien die organiese eenheid en vervlegtheid van uitleg (aanwending van die historiese teks) en toepassing (inskakeling by konkrete situasie) nog nie bereik is nic, is die preek nog nie voltooi nie of selfs nog nie gevind nie. Runia wys in hierdie verband daarop dat die gaping tussen die historiese teks en die eietydse situasie nie oorspan moet word nie (exaggerating the gap) (1983:79). Hy verwys na Lange wat beweer dat die uniekheid van die huidige situasie die historiese teks fully irrelevant maak (1983:80). Alhoewel die huidige situasie uniek is (Duits: einmalig), is dit beslis nie uitsonderlik (Duits: erstmalig) nie. Die kerk leef immers deur die eeue in prinsipe met dieselfde geestelike gawes en veg teen dieselfde soort sondes (bv. materialisme, egoīsme). 'n Kontinuiteit tussen teks en situasie is aanwysbaar.

Daar is egter beslis ook diskontinuïteit. Die waarheid word erken in die omkering van die vorige stelling: alhoewel 'n situasie nie erstmalig is nie, is dit tog einmalig. Ons leef eenvoudig nie in 1200 $\mathrm{vC}$ of $80 \mathrm{nC}$ nie, maar in 'n snelveranderende twintigste eeu. Hoe om hierdie gaping gevul te kry, is 'n brandende vraagstuk en die crux van die prediking.

Runia vind die oplossing by Calvyn wat in sy nadenke oor die verhouding Godsopenbaring en Skrifwoord gespreek het van die accommodation van die waarheid in die Bybel in die sin van: God in his revelation condescends to our level (vgl. Runia, 1983:83). So akkommodeer die evangelie hom in elke situasie deur die Gees sonder om sy krag of karakter te verloor - analoog aan Christus se menswording (Bavinck). Uit bogenoemde blyk hoedanig die prediker die Skrif ten volle moet erken en honoreer in sy prediking, maar eweseer sy eie tyd en die adres van die prediking moet ken. Alleen só kan die evangelie hom in die twee-eenheid van uitleg en toepassing in die situasie akkommodeer.

'n Laaste opmerking onder hierdie subhoof word gewy aan die standpuntinname dat die telos (doel, oogmerk; Van der Walt, 1983 : 40 -1) van ' $n$ Skrifdeel in die preek verdiskonteer moet word om as instrument van die Gees kan dien. Dit raak die kwessie van Skrifgebruik en tekskeuse in die prediking. Wanneer die preekdoel teen die telos (teksdoel) ingaan, word die preek ontkrag en verloor dit sy gesag (vgl. Jonker, 1976:46). Die Skrif mag nie aangewend word bloot om 'n gepaste woord, gedagte, boodskap of dogma deur te gee nie. Blote Woord- of gedagteooreenkomste beteken nog nie telos-ooreenkoms nie. Ten opsigte hiervan word baie gesondig 
omdat die Skrif, vir die aanwending in prediking nie in sy breër verbande gelees en bestudeer word nie.

\section{SAMEVATTEND}

Die wese van die prediking is dat dit God self is wat deur sy dienskneg tot sy gemeente spreek. Die spreke vind plaas deur uitleg van die Bybelteks, gekoppel aan toepassing as 'n twee-eenheid, in die konkrete situasie vandag. Hiervoor is die verligtende kontinue werking van die Heilige Gees onmisbaar. Om as instrument van die Gees en die Woord te kan optree, moet die situasie vanuit die telos van die Skrif benader word en nie andersom nie. Die gawe van die Gees is nodig om die spreke van God in die verlede te laat weerklink in die hede.

\section{PREDIKING VAN DIE BELYDENISSKRIFTE}

Die prediking van die Heidelbergse Kategismus (HK) en ander belydenisskrifte veroorsaak vir eeue reeds allerlei homiletiese probleme. Iemand soos Lloyd-Jones verklaar openlik dat hy die HK nie preek nie, maar wel aan die gemeente doseer by ander geleenthede as eredienste (1971:187 e v).

Die volgende homiletiese probleme t.o.v. die preek van die HK word aangedui:

a) Die teks van die $\mathrm{HK}$ kan moeilik as preekteks geneem word aangesien dit in stryd is met die wese van prediking, naamlik dat God alleen deur sy eie Woord aan die woord mag kom (vgl. subdeel: wese van die prediking; Grobler: $1983: 99 \mathrm{ev}$ ). Al is dit ge. kontroleerde waarheid wat in die HK (en ander belydenisskrifte) bely word, en ten volle konform die Skrif, maak dic HG (c a.) nog nie die Woord van God uit nie; trouens, die belydenisskrifte bly appellabel aan die Skrif en is as sodanig opgestel onder verligting van die Gees en nie deur sy inspirasie nie (vgl. 2 Tim $3: 16$; 2 Pet $1: 20)$.

b) Die HK (e.a.) het 'n eie skopus. So is die HK se skopus in soteriologies-pastorale terme te vind (Wat is jou enigste troos? $\mathrm{Vr} 1$ ). Hierdie skopus word baie noulettend op 'n logiese wyse uitgebou, sodat selfs aangetoon word dat die dankbaarheid van die gelowige ' $n$ voorwaarde tot sy troos is (HK vr 2). Dit is 'n homiletiese probleem om 'n preekteks te vind waarin die skopus van die Skrifdeel ooreenstem met die skopus van die HK (volgens die onderdele van die Sondagindelings). In die geval van ander belydenisskrifte is dit nog 'n groter probleem aangesien die formulering van die belydenis nie op die eksistensiële behoeftes van die gemeente afgestem is, soos in die HK nie (vgl. Jonker, 1976:133-4). Die homiletiese vereiste is dat skopus van die Skrifdeel en die van die situasie (in hierdie geval ' $n$ bepaalde belydenis) moet ooreenstem (vgl. subdeel: wese van die prediking). Ook al is die "belydenisprediking" as didaktiese prediking aan te dui, mag dit die wese van prediking nie verwring nie.

c) Die materie van die HK (e.a.) kan die prediker maklik van die inhoud van sy prediking weglei, naamlik deur nie God se selfopen- 
baring te verkondig nie, maar 'n bepaalde belydenisdeel, leerstuk of dogma (vgl. subdeel: inhoud van die prediking).

d) Die standpunt word soms gehoor dat die eintlike belydenis nie in die teks van die HK (e.a.) te vind is nie, maar in die aangebringde Skrifverwysinge wat as bymekaarhorende Skrifprediking geneem moet word (vgl. d'Assonville, 1976:76). Inderdaad gee die Skrifverwysinge goeie begrondinge vir die belydenisformulering - oor die algemeen gesproke - maar die geskiktheid daarvan as preektekse vir die besondere belydenis is daarmee nog nie bewys nie, inteendeel, die teksverwysinge is moeilik as 'n eenheid te neem (versus d'Assonville, 1959:78), aangesien die (Skrif-)skopus van hierdie tekste soms grootliks verskil.

Samevattend kan gevra word of die HK (c.a.) werklik met volle honorering van alle homiletiese prinsipiae, "preekbaar" is. Is die kategismuspreke wat in verskeie homiletiese werke te vind is, wel preke?

$\mathrm{Na}$ ons eie beskeie oordeel is dit wel moontlik om ' $\mathrm{n}$ bepaalde afdeling van die HK (e.a.) in 'n ware preek deur te gee, aangesien dit wat bely word na inhoud en skopus vo!kome ooreenstem met Skrifverkondiginge en bepaalde Skriftekste/perikope (vgl. Antw 5 en Rom $7: 12-24)$. Daar is egter ander gevalle waar 'n Sondagafdeling moeilik met slegs een of twee Skrifdele gepreek kan word (vgl. Sondag 4,5). Dit is 'n aanduibare probleem dat die skopus van die bepaalde belydenisonderdeel en die skopus van die Skrifberoep nie oral volledig ooreenkom nie.

\section{EINDKONKLUSIE}

Die belydenisskrifte as sodanig mag nie gepreek word nie, dit bots met die wese, sowel as inhoud van die prediking. Daar mag sekerlik aan die hand van die belydenis (situasie) gepreek word vanuit en op grond van die Skrif. Die preektekste hoef nie beperk te word tot die Skrifberoep by die belydenisse self nie - aangesien die opstellers sekerlik nie gestreef het na volledigheid nie. Die prediking mag ook nie die skopus van die belydenisskrifte volg nie, maar wel die skopus van die Skrifteks.

Die prediking van die belydenisskrifte besit 'n buitengewoon belangrike en verhewe doel, naamlik om die volle evangelie te laat verkondig en die eenheid van die kerk te bewaar en verder uit te bou. $\mathrm{Om}$ in hierdie verhewe doel te kan slaag moet álle prediking Skrifprediking bly.

\section{SLOT}

Ten slotte word 'n definisie van die prediking gewaag, wat as 'n samevattende eindkonklusie gesien kan word:

Die prediking is die Geestelike bediening van die Woord van God tot openbaring van God, volgens 'n preekdeel, in ooreenstemming met die preekdeelskopus, in ' $n$ bepaalde konkrete situasie, deur 'n geroepe dienskneg aan veral dic gemeente van God (Geesbesitters). 


\section{BIBLIOGRAFIE}

Biesterveld, $P$ 1894. Het hooge belang der ambtelijke vakken. Kampen: Kok. Calvyn, J 1956. Institutie of onderwijzing in de Christelijke Godsdienst. Ver taal deur Sizoo, A. Vierde druk. Deel 1-3. Delft: Meinema.

Coetzee, J C 1985. Drie wesenlike elemente van egte prediking - indikatief, imperatief en belofte In: Van der Walt, J J (red): God aan die Woord; p. 17-28. Potchefstroom: Dept Diakoniologie.

d'Assonville, V E 1976. Die dwaasheid om te preek. Johannesburg: De Jong.

De Klerk, J J 1977. Prediking. Pretoria: NGK Boekhandel.

Friedrich, G 1965. Kerussein. In: Kittel, G (red): Theological dictionary of the New Testament. Volume III : 703-9. Michigan: Eerdman*.

Grobler, C S 1983. Kategismusprediking - is dit Skrifprediking? Th M - PU vir CHO.

Harder, G 1969. Prediking. In: Buytendijk, F J J (red): Bijbels-historisch Woordenboek. Deel IV: $162-165$. Antwerpen: Spectrum

Hoekstra, T s.j. Gereformeerde Homiletiek Wageningen: Zomer en Keuning.

Jonker, H 1960. Prediking In: Grosheide, F W en Van Itterzon, G P (red): Christelijke Encyclopedie. Deel 5:500. Kampen: Kok.

Jonker, W D 1976. Die Woord as opdrag. Pretoria: NGK Boekhandel.

Knox, J 1957. The integrity of preaching. London: Epworth Pres;

Kotzé, G J 1963. Hedendaagse Skrifprediking: 'n Onderzoek na die mistastinge in die prediking van die nuwere tyd. Proefskrif US. Potchefstroom: Pro Rege Pers.

Lloyd-Jones, D M 1971. Preaching and preachers. London: Hodder and Stoughton.

Muller-Bardorff, J 1969. Preek. In Buytendijk, F J J (red). Bijbels-historisch Woordenboek: Deel IV : 166-8. Antwerpen: Spectrum.

Runia, K 1983. The sermon under attack. In: The Moore College Lectures 1980. Exeter: Paternoster Press.

Van der Walt, J J 1983. Homiletiek I en II: Prinsipiële deel. Klasdiktaat. PU vir CHO, Potchefstroom.

Van der Walt, J J (red) 1985. God aan die Woord: Lesings voor die seminaar oor Bybelse prediking, 20-24 Februarie 1984. Potchefstroom: Dept Diakoniologie. 